\title{
INFLUENCE OF ELECTRICITY TARIFFS ON OPTIMAL SOLAR COLLECTORS ORIENTATION IN NEGEV REGION
}

\author{
Muhannad Shahbari ${ }^{1}$, Karam Sadi ${ }^{1}$, Sergei Kolesnik ${ }^{1}$, Moshe Sitbon ${ }^{2}$, Alon Kuperman ${ }^{1,2}$ \\ ${ }^{1}$ Ben-Gurion University of the Negev, Israel; ${ }^{2}$ Ariel University of Samaria, Israel \\ muhanads@post.bgu.ac.il,karams@post.bgu.ac.il,skolesnik@gmail.com, sitbon222@gmail.com, \\ alonk@bgu.ac.il
}

\begin{abstract}
In case of fixed electricity tariffs, fixed-orientation solar collectors in grid-connected systems are typically positioned to the south, tilted approximately at location latitude. Such orientation maximizes annual energy and hence the total income. On the other hand, in case of time-varying feed-in tariffs the maximum annual energy yield does not necessarily correlate with the maximum income. Therefore, in order to shorten the rate of return, both the tilt and azimuth of solar collectors should be varied accordingly. The paper demonstrates a case study for Negev region of Southern Israel, based on clear sky irradiation model and current feed-in tariffs. In order to estimate a typical annual energy yield, 1-hour-resolution irradiation data are used in order to obtain the power output of a typical solar panel with similar resolution. A typical losses model is employed to improve the prediction accuracy. Correspondent temperature and wind speed data are also utilized to account for temperature-induced de-rating. The results may also be used to indicate the feasibility of the feed-in tariffs to avoid economical imbalance. It is shown that unlike in previously described cases, a similar rate of return for both maximum energy and maximum income orientation are obtained in Israel, demonstrating excellent choice of feed-in tariffs for solar energy in Israel.
\end{abstract}

Keywords: solar energy, feed-in tariff, optimal orientation.

\section{Introduction}

In order to maximize the annual fed-in energy generated by fixed-orientation photovoltaic generators, the panels should be oriented towards the south (north) in the Northern (Southern) Hemisphere and the tilt should be equal to the latitude [1] (as a rule of thumb), in case clear-sky conditions are assumed. In practice, many factors may affect the optimal orientation for particular locations, such as cloudiness, temperature, shading, dust, rain, snow, bird droppings etc. [2].

Maximization of fed-in energy is equivalent to maximizing the revenue in case of a constant feedin tariff, typical for many grid-connected systems. Consequently, typical optimization of photovoltaic performance focuses on maximizing the annual energy production [3]. In this paper, grid-connected systems only are considered; yet, it should be emphasized for the sake of completeness that in off-grid systems, maximizing the total energy generated may be of secondary importance, while, e.g. obtaining a uniform power output throughout specific period (day/month./season/year etc.), may be much more significant [4].

However, in case the feed-in tariff varies daily and seasonally, the panel orientation yielding the maximum annual energy may not yield the maximum economic benefit $[5 ; 6]$. The authors of [7] quantified the impact of such tariffs on the optimal orientation of non-tracking PV modules using example tariffs from California, Nevada and Ontario, and concluded that modules should be oriented to the west of south by $28^{\circ}, 46^{\circ}$ and $54^{\circ}$ respectively. Compared to conventional south facing modules tilted at an angle just under the latitude, the outcomes have demonstrated that optimal orientation adds 4-19\% to the revenue/cost savings, potentially affecting the economic viability of the installation. In [8] it has been observed that for Las Vegas orienting photovoltaic systems azimuth $52^{\circ}$ west of the south improves the internal rate of return by 1.16, compared to the systems facing the south. However, the same paper indicates that for 25 locations analysed in the USA an economically optimized PV system does not yield significant rate of return improvement in case the optimized azimuth is less than $20^{\circ}$ west of the south. In [9] the authors have shown that feed-in tariff and self-consumption (in case of domestic installation) may greatly affect the financially optimal orientation of photovoltaic systems. On the other hand, the authors of [10] have concluded that, although adjustments of photovoltaic installation angles can reduce the total electricity generation costs, the impact is very small, even if the installed capacity doubles in Austria and Germany. Angle combinations that aim at maximizing the output of a photovoltaic system throughout the year will still lead to almost minimal generation costs of the whole system in the medium term. 
It may then be concluded that even in case the optimal orientation in terms of the annual energy yield does not coincide with the optimal orientation in terms of the annual financial benefit, the difference in terms of return of the investment may be negligible. Therefore, each specific location must be examined, taking into account the relevant meteorological data and feed-in tariffs. Consequently, this paper demonstrates a case study for Negev region of Southern Israel, based on a clear sky irradiation model and current feed-in tariffs in Israel.

\section{Materials and methods}

1. Location.

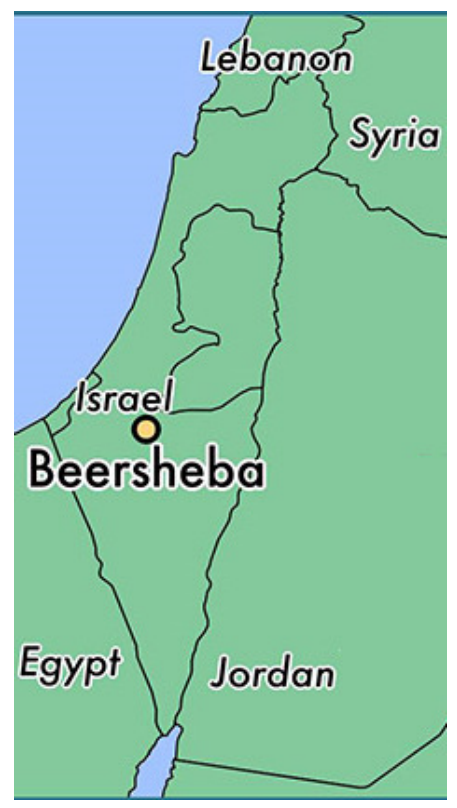

Fig. 1. Beer-Sheba location

Beer-Sheba is the capital of the Negev region of Southern Israel, as shown in Fig. 1. It is located 31.25 latitude and 34.79 longitude, situated at elevation 285 meters above the sea level.

2. Electricity Tariffs.

High voltage network tariffs set by the Israel Electric Company are considered (including $17 \%$ VAT), as summarized in Table 1.

Electricity Tariffs (High Voltage) in Israel, 1 ILS = 0.28 USD

\begin{tabular}{|c|c|c|c|}
\hline Month / Time & Peak & Average & Low \\
\hline & & & $00: 00-06: 00$ \\
December - & $16: 00-22: 00$ & $06: 00-08: 00$ & $08: 00-16: 00$ \\
February & 0.2740 USD per kWh & 0.1632 USD per kWh & $22: 00-00: 00$ \\
& & & 0.0971 USD per kWh \\
\hline March - June & $06: 00-20: 00$ & $20: 00-22: 00$ & $00: 00-06: 00$ \\
September - & 0.1301 USD per kWh & 0.1061 USD per kWh & $22: 00-00: 00$ \\
November & $10: 00-17: 00$ & $07: 00-10: 00 \&$ & 0.0863 USD per kWh \\
\hline & 0.3032 USD per kWh & $17: 00-21: 00$ & $21: 00-00: 00$ \\
July - August & 0.1322 USD per kWh & 0.0889 USD per kWh \\
& \multicolumn{3}{|c}{} \\
\hline
\end{tabular}

3. Clear sky model.

The model [1] considers the orientation of the earth relative to the sun and the apparent extraterrestrial flux. It assumes an empirically fitted relation between the air mass ratio and beam radiation, while taking into account the tilt and azimuth of the solar panel, the angle between the module and the beam radiation and the way in which diffuse irradiance varies with the time of the year. It also 
includes the reflected irradiance due to reflection of both beam and diffuse irradiance by the surface in front of the solar panel. The complete model is described in [1, pp. 388-418] and the equations are summarized in [1, pp. 423-4].Incidence angle modifiers [11] were also considered in this work to improve the accuracy of the results.

The resulting irradiance is then converted into hourly electric power yield, taking into account the corresponding hourly wind speed and temperatures, using a typical loss model for both the panel itself and the system losses (cabling, inverters etc.) [12]. Hourly electrical power yield is then linked to the tariff applicable at that particular time to calculate the corresponding hourly revenue. Both the net yearly energy generation and monetary revenue as a function of the panel tilt and azimuth are found by summing the hourly revenue over an entire year for a range of all possible installation tilts and azimuth angles.

\section{Results and discussion}

For Beer-Sheva region the maximum energy yield was obtained for the orientation given by the tilt angle of $28^{\circ}$ (slightly lower than the location latitude) and the azimuth angle of $0^{\circ}$ to the south (operating point 1 in Fig. 2). The annual revenue per $1 \mathrm{~kW}$ installed was found to be270.09 USD. On the other hand, optimizing the revenue for the tariff given by Table 1 yielded the orientation characterized by the tilt angle of $25^{\circ}$ and azimuth angle of $-9^{\circ}$ (west) to the south (operating point 2 in Fig. 2).The annual revenue per $1 \mathrm{~kW}$ installed was found to be 271.09 USD. It may then be concluded that both installations yield nearly the same monetary revenue. Moreover, in order to examine the sensitivity of monetary revenue to the orientation, the range of the azimuths and tilts yielding more than $99 \%$ of the optimal revenue was found. It was concluded that reorienting the installation within $\pm 15^{\circ}$ in azimuth and $\pm 10^{\circ}$ in tilt would still yield at least $99 \%$ of the optimal revenue, see Fig. 2. Such results well support the electricity tariffs set by the Electricity Authority of Israel.

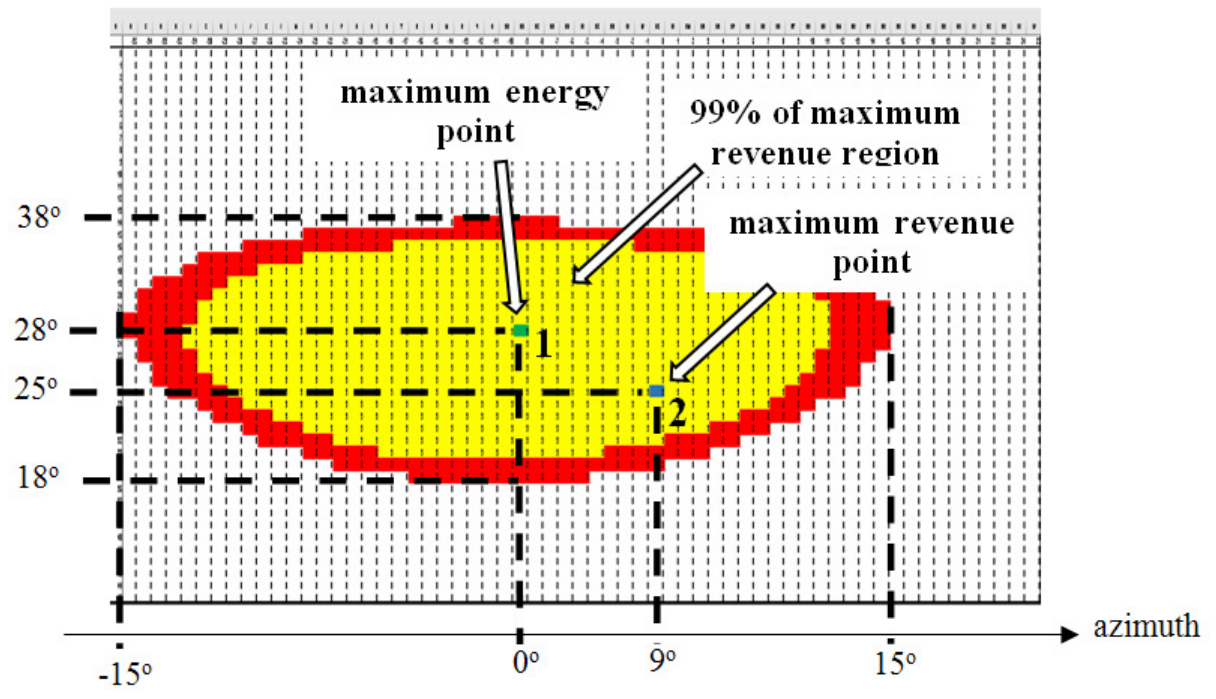

Fig. 2. Operation region (Blue dots are the two optimal points, while the red region indicates the range of tilts and azimuths yielding at least $99 \%$ of the optimal annual monetary revenue)

\section{Conclusions}

It was shown that a similar rate of return ( $0.37 \%$ difference) for both the maximum energy and maximum income orientation is obtained in the Negev region of Southern Israel, based on a clear sky irradiation model and high voltage electrical network feed-in tariffs. In addition, the results indicate that reorienting the installation within $\pm 15^{\circ}$ in azimuth and $\pm 10^{\circ}$ in tilt would still yield at least $99 \%$ of the optimal revenue, demonstrating extremely low sensitivity of the revenue around the optimal point. The 1-hour-resolution irradiation data were used to obtain the power output of a representative solar panel, employing a typical losses model to improve the prediction accuracy. Moreover, the typical regional temperature and wind speed were utilized to account for temperature-induced derating. The results validate the current feed-in tariffs to preserve economical balance. 


\section{References}

[1] Masters G. Renewable and efficient electric power systems, New Jersey: John Wiley \& Sons Inc., 2004.

[2] Ghazi S., Ip K. The effect of weather conditions on the efficiency of PV panels in southeast of UK. Renewable Energy, vol. 69, 2014, pp. 50-59.

[3] Yadav A. K., Chandel S. S. Tilt angle optimization to maximize incident solar radiation: A review. Renewable Sustainable Energy Reviews, vol. 23, 2013, pp. 503-513.

[4] Mehleri E.D., Zervas P.L., Sarimveis H., Palyvos J.A., Markatos N.C. Determination of the optimal tilt angle and orientation for solar photovoltaic arrays. Renewable Energy, vol. 35, 2010, pp. 2468-2475.

[5] Hummon M., DenholmP., Margolis R. Impact of photovoltaic orientation on itsrelative economic value in wholesale energy market. Progress in Photovoltaics:Research and Applications, vol. 21, 2013, pp. 1531-1540.

[6] Rowlands I. H., Kemery B. P., Beausoleil-Morrison I. Optimal solar-PV tilt angle and azimuth: An Ontario (Canada) case-study. Energy Policy, vol. 39, 2011, pp. 1397-1409.

[7] HaysomJ. E., HinzerK., WrightD.Impact of electricity tariff on optimal orientation of photovoltaic modules. Progress in Photovoltaics: Research andApplications, vol. 24, 2016, pp. 253-260.

[8] Toomsk S., Haysom J. E., Hinzer K., Schriemer H., Wright D. Mapping the geographic distribution of the economic viability of photovoltaic load displacement projects in SW USA. Renewable Energy, vol. 107, 2017, pp. 101-112.

[9] Litjens G. B. M. A., Worrell E., van Sark W. G. J. H. M. Influence of demand patterns on the optimal orientation of photovoltaic systems. Solar Energy, vol. 155, 2017, pp. 1002-1014.

[10] Hartner M., Ortner A., Hiesl A., Haas R., East to west - The optimal tilt angle and orientation of ohotovoltaic panels from and electricity system perspective. Applied Energy, vol. 160, 2015, pp. 94-107.

[11] Strobach E., Faiman D., Bader S. J., Hile S. J. Effective incidence angles of sky-diffuse and ground-reflected irradiance for various incidence angle modifier types. Solar Energy, vol. 89, 2013, pp. 81-88.

[12] Solomon A. A., Faiman D., Meron G. An energy-based evaluation of the matching possibilities of very large photovoltaic plants to the electricity grid: Israel as a case study. Energy Policy, vol. 38, 2010, pp. 5457-5468. 